\title{
Impact of 25-hydroxyvitamin D, free and bioavailable fractions of vitamin D, and vitamin D binding protein levels on metabolic syndrome components
}

\author{
Marta Pelczyńska ${ }^{1}$, Teresa Grzelak ${ }^{1}$, Marcelina Sperling ${ }^{1}$, Paweł Bogdański², \\ Danuta Pupek-Musialik³, Krystyna Czyżewska ${ }^{1}$
}

\begin{abstract}
${ }^{1}$ Division of Biology of Civilization-Linked Diseases, Department of Chemistry and Clinical Biochemistry, Poznan University of Medical Sciences, Poznan, Poland ${ }^{2}$ Department of Education and Obesity Treatment and Metabolic Disorders, Poznan University of Medical Sciences, Poznan, Poland ${ }^{3}$ Department of Internal Medicine, Metabolic Disorders and Hypertension, Poznan University of Medical Sciences, Poznan, Poland
\end{abstract}

Submitted: 1 October 2015

Accepted: 12 December 2015

Arch Med Sci 2017; 13, 4: 745-752

DOI: https://doi.org/10.5114/aoms.2016.58594

Copyright @ 2016 Termedia \& Banach

\section{Abstract}

Introduction: Various forms of vitamin D and factors involved in their metabolism can play a role in the etiopathogenesis of metabolic disorders. This paper aims to define the relationship between concentration of the hydroxylated form of vitamin $D(25(\mathrm{OH}) \mathrm{D})$, the fraction of free and bioavailable vitamin D, and of vitamin D binding protein (VDBP) levels on the one hand and the prevalence of metabolic syndrome components on the other.

Material and methods: The studies were conducted on 79 people, including 52 with metabolic syndrome (MetS+) and 27 without it (MetS-). Biochemical measurements (lipid profile, glycemia, 25(OH)D, VDBP, albumin, calcium, parathyroid hormone) were performed, concentration of free and bioavailable vitamin D was mathematically calculated, and anthropometric and blood pressure measurements were taken.

Results: The mean \pm SD concentration of $25(\mathrm{OH}) \mathrm{D}$ among MetS+ individuals $(41.90 \pm 13.12 \mathrm{nmol} / \mathrm{l})$ was lower $(p<0.0001)$ than among the MetS-group $(66.09 \pm 18.02 \mathrm{nmol} / \mathrm{l})$. Differences between groups were observed in relation to medians/means of concentrations of free and bioavailable vitamin D $(p<0.0001)$ but not in the case of VDBP. In the entire study population, $25(\mathrm{OH}) \mathrm{D}$ correlated with all metabolic syndrome components, whereas its free and bioavailable fraction correlated with particular components of the syndrome. In the MetS+ group, VDBP concentration negatively correlated with body mass index $(p=0.037)$ and levels of diastolic pressure $(p=0.022)$. In the case of the MetS- group, the free fraction of vitamin D negatively correlated with triglyceridemia $(p=0.049)$.

Conclusions: The evaluation of various forms of vitamin D and VDBP in different population groups seems to have significant clinical value in evaluating the prevalence of metabolic disorders.

Key words: forms of vitamin D, vitamin D binding protein, metabolic syndrome.
Corresponding author: Marta Pelczyńska MS Division of Biology of Civilization-Linked Diseases

Department of Chemistry and Clinical Biochemistry Poznan University of Medical Sciences 6 Święcickiego St 60-781 Poznan, Poland Phone: +48 618546476 Fax: +48 618546477 E-mail: mpelczynska@ump.edu.pl

\section{Introduction}

Metabolic syndrome includes a number of disorders whose coexistence increases the risk of development of, among others, atheroscle- 
rotic cardiovascular system diseases and type 2 diabetes mellitus. The pathogenesis of metabolic syndrome (MetS) has not been fully explained [1]. Recently, attention has been paid to the presence in the human body of various forms of vitamin $D$ and their participation in the etiology of civilization-related diseases. The various forms of vitamin $D$ include not only its hydroxylated form $(25(\mathrm{OH}) \mathrm{D})$, but also the free and bioavailable fraction of this vitamin, as well as factors engaged in its metabolism such as the so-called membrane transport protein (Gc-globulin).

Vitamin $D$ is responsible for regulating the expression of many genes (at the level of transcription or by membrane receptors) that are mainly associated with the homeostasis of calcium and phosphate, carbohydrates, and lipids, as well as with the immune response or anticancer activity [2]. The appropriate concentration of vitamin $D$ is important in many diseases, including abdominal obesity, type 2 diabetes mellitus, and dyslipidemia [3, 4]. It is believed that excessive body weight is a significant factor that leads to lower serum concentrations of the vitamin. Moreover, the complex metabolism of vitamin $D$, including its transformations and transport, determines its total and bioavailable pool, and it also depends on the calcium and parathyroid hormone concentrations in the blood $[3,5,6]$.

Several forms of vitamin $\mathrm{D}$ can be distinguished in the human body. About $88 \%$ of the $25(\mathrm{OH}) \mathrm{D}$ and $85 \%$ of the $1,25(\mathrm{OH}) \mathrm{D}$ are bound to vitamin $\mathrm{D}$ binding protein, and a further $10-13 \%$ to albumin. The rest constitutes the so-called free fraction of vitamin D, which is not bound to serum proteins. Together with the vitamin D bound to albumin, this makes up the bioavailable fraction. It should be noted that free vitamin $D$, although it constitutes only a small percentage (0.1-2\%) of the total vitamin in all forms in the human body, is characterized by high biological activity (in accordance with the "free hormone hypothesis", only unbound molecules can freely migrate through cell membranes and cause particular metabolic effects) [7].

One of the substances responsible for the transport of vitamin D is Gc-globulin, also called vitamin $\mathrm{D}$ binding protein (VDBP). This is a glycoprotein with multidirectional activities. Unlike 25(OH)D, VDBP is probably not subject to seasonal variations [8,9]. Research based on knocking out the gene coding for Gc-globulin in mice has shown that this protein has a significant impact on vitamin D activity. The animals were characterized by lower concentrations of hydroxylated forms of this vitamin in the blood (both 25-hydroxyvitamin D, and 1,25-dihydroxyvitamin D) than were mice with the properly functioning gene [10]. The relation between the level of VDBP and the concentration of $25(\mathrm{OH}) \mathrm{D}$ in the blood has also been demonstrated in humans $[11,12]$. However, to date, there have been no evaluations of the concentration of the various forms of vitamin $D$ and of vitamin $D$ binding protein in the population of people with metabolic syndrome.

The aim of the study was to identify and evaluate the relationship of $25(\mathrm{OH}) \mathrm{D}$ concentration, the fraction of free and bioavailable vitamin $D$, and the level of vitamin D binding protein, on one hand, with the prevalence of metabolic syndrome components, on the other.

\section{Material and methods}

The research was approved by the Local Ethical Committee (no. 456/14).

\section{Research group}

Based on the consensus of the International Diabetes Federation and the American Heart Association and the National Heart, Lung, and Blood Institute from 2009 [13], the study includes a harmonized definition of metabolic syndrome. MetS was diagnosed based on the presence of at least three of the five components of this syndrome. The components of MetS included: waist circumference greater than $94 \mathrm{~cm}$ for men and $80 \mathrm{~cm}$ for women, increased level of fasting glycemia (> $5.6 \mathrm{mmol} / \mathrm{l}$ ), increased arterial blood pressure ( $>130 \mathrm{~mm} \mathrm{Hg}$ for systolic pressure or $>85 \mathrm{~mm} \mathrm{Hg}$ for diastolic pressure), hypertriglyceridemia ( $>1.7$ $\mathrm{mmol} / \mathrm{l})$, and lowered levels of high-density lipoprotein $(\mathrm{HDL})$ cholesterol $(<1.0 \mathrm{mmol} / \mathrm{l}$ for men and $<1.3 \mathrm{mmol} / /$ for women), or adequate drug therapy for hyperglycemia, hypertonia arterialis, or dyslipidemia [13]. The study included 79 Caucasians aged 30-60 years. The research group consisted of 52 people with metabolic syndrome (MetS+), all patients of the Department of Internal Medicine, Metabolic Disorders and Hypertension, Poznan University of Medical Sciences. Twenty-seven volunteers without metabolic syndrome (MetS-), matched for age and gender, formed the control group. In the MetS+ group, $30.75 \%$ of people met five of the criteria for metabolic syndrome, 38.50\% met four, and $30.75 \%$ met three. In the MetSgroup, $25.93 \%$ of the population met two criteria (most often slightly increased waist circumference and level of arterial blood pressure) and 37.04\% met only one (most often slightly increased level of arterial blood pressure). Recruitment for the research and control groups was performed simultaneously for 20 months starting in March 2013.

\section{Anthropometric and biochemical measurements}

Measurement of the height and mass of the participants, fasting and dressed only in under- 
wear, was carried out using a stadiometer and a certified electronic scale (SECA 285 Wireless, Hamburg, Germany). The measurements of waist circumference (measured midway between the costal arch and the upper iliac crest) and of hip circumference (at the level of the greater trochanters) were made. The obtained results were used to calculate the body mass index (BMI) and the waist-to-hip ratio (WHR). Measurements of arterial blood pressure (systolic/diastolic, SBP/DBP respectively) were repeated three times with the patient sitting, and after at least a 10-minute rest, using a certified sphygmomanometer (model 705IT, Omron Corporation, Kyoto, Japan) in accordance with the recommendations of the European Society of Hypertension and the European Society of Cardiology [14].

Blood samples were taken in the morning and either used immediately for testing or saved and frozen at a temperature of $-20^{\circ} \mathrm{C}$. Indicators of fasting blood glucose (FBG) and lipid profile, such as total cholesterol (TC), HDL fraction, and triglyceride level (TG), were measured using enzymatic methods and standardized tests performed at the clinical laboratory in Poznan. Because triglyceridemia was defined as a TG level below $4.52 \mathrm{mmol} / \mathrm{l}$, the concentration of low-density lipoprotein (LDL) was calculated based on the following formula: $\mathrm{LDL}=\mathrm{TC}-(\mathrm{HDL}+\mathrm{TG} / 5)$. The total concentration of 25(OH)D (25-hydroxyergocalciferol and 25-hydroxycholecalciferol) was evaluated using the electrochemiluminescence method on a cobas e immunoanalyzer (Roche Diagnostic, Mannheim, Germany); the total calcium was evaluated using the complexometric method on a Roche/Hitachi cobas e system (Roche Diagnostic, Mannheim, Germany), and parathyroid hormone levels were determined with the immunoradiometric method (Immunotech, Marseille, France). An automated technique using bromocresol green was performed in order to measure albumin concentration (Abbott Laboratories, Irving, Texas, U.S.A.). The serum concentration of vitamin D binding protein was identified using the ELISA method in accordance with the manufacturer's instructions (DRG Instruments $\mathrm{GmbH}$, Marburg, Germany).

\section{Calculating free and bioavailable vitamin D}

The concentration of the free fraction of $25(\mathrm{OH}) \mathrm{D}$ in the blood serum was calculated in accordance with the following formula [15]: free $25(\mathrm{OH}) \mathrm{D}$ $[\mathrm{pmol} / \mathrm{l}]=25(\mathrm{OH}) \mathrm{D} / 1+\left(6 \times 10^{3} \times\right.$ [albumin $\left.]\right)+$ $\left(7 \times 10^{8} \times[\mathrm{VDBP}]\right)$.

The concentration of bioavailable vitamin $D$ was calculated using this equation [16]: bioavailable $25(\mathrm{OH}) \mathrm{D}[\mathrm{nmol} / \mathrm{l}]=\left(\mathrm{K}_{\mathrm{alb}} \times[\right.$ albumin $\left.]+1\right) \times[$ free $25(\mathrm{OH}) \mathrm{D}]$, where $\mathrm{K}_{\mathrm{alb}}$ is a constant for $25(\mathrm{OH}) \mathrm{D}$ binding with albumin $\left(6 \times 10^{5} \mathrm{~mol}^{-1}\right)$.

\section{Statistical analysis}

The obtained research results were subjected to statistical analysis, including elements of descriptive statistics and statistical procedures, such as correlation and regression analysis of the studied variables and analysis of variance. The statistical analysis of the results was performed using Statistica 10.0 (StatSoft Inc., Tulsa, OK, USA) program. Normal data distribution for smaller groups was proved using the Shapiro-Wilk test, while for groups of over 50 people, the Kolmogorov-Smirnov test was used. The level of statistical significance was set at $p<0.05$.

\section{Results}

The results of the anthropometric analysis showed, as expected, statistically significant differences in the body composition of individuals from the MetS+ and MetS- groups. The individuals with metabolic syndrome were characterized by notably higher mean body weight, waist circumference, and BMI than those without the syndrome. The results of the biochemical analysis revealed statistically significant differences in the concentration medians (or mean values) of metabolic syndrome components (SBP, DBP, HDL, TG, FBG) between the individuals with MetS+ and the people without the syndrome (Table I). In the case of total cholesterol concentration $(p=0.062)$ and LDL fraction ( $p=0.07$ ), the differences between the analyzed groups (MetS+ vs. MetS-) were not significant.

The mean \pm SD concentration of $25(\mathrm{OH}) \mathrm{D}$ in patients with metabolic syndrome was significantly lower $(p<0.0001)$ than among those lacking the syndrome, and was $41.90 \pm 13.12 \mathrm{nmol} / \mathrm{l}$ for MetS+ and $66.09 \pm 18.02 \mathrm{nmol} / /$ for MetS- (Table II). In line with the 2011 recommendations of the Endocrine Society regarding the "Evaluation, treatment, and prevention of vitamin $D$ deficiency" [17], vitamin D deficiency $(<50 \mathrm{nmol} / \mathrm{l})$ can be observed in the group of individuals with metabolic syndrome, whereas in the MetS- group, the concentration was at an insufficient level (50-75 nmol/l). Statistically significant differences $(p<0.0001)$ between the groups were also observed in the case of the concentration of free and bioavailable vitamin $D$, and in that of albumin in the serum $(p<0.0001)$. There were no differences in the levels of vitamin D binding protein, calcium, or parathyroid hormone between patients with metabolic syndrome and those without it (while maintaining the reference values of the parameters).

In the entire studied population ( $n=79)$, the concentration of $25(\mathrm{OH}) \mathrm{D}$ was significantly correlated with anthropometric markers (body weight, BMI, WHR) and with the biochemical 
Table I. Anthropometric and biochemical characteristics of studied individuals with (MetS+) and without metabolic syndrome (MetS-)

\begin{tabular}{|lccccc|}
\hline Parameter & \multicolumn{2}{c}{ MetS+ $(n=52)$} & \multicolumn{2}{c}{ MetS- $(n=27)$} & $P$-value \\
\hline Body weight $[\mathrm{kg}]$ & $109.98 \pm 22.28$ & $105.20(95.23 ; 122.58)$ & $71.84 \pm 15.84$ & $71.30(58.70 ; 85.95)$ & $<0.0001$ \\
\hline $\begin{array}{l}\text { Waist } \\
\text { circumference } \\
\text { [cm] }\end{array}$ & $116.71 \pm 14.56$ & $113.50(104.00 ; 128.00)$ & $82.63 \pm 10.87$ & $82.00(73.50 ; 91.50)$ & $<0.0001$ \\
\hline $\begin{array}{l}\text { Hip } \\
\text { circumference } \\
\text { [cm] }\end{array}$ & $119.73 \pm 13.93$ & $119.50(108 ; 130.50)$ & $98.89 \pm 6.88$ & $99(93.50 ; 105.50)$ & $<0.0001$ \\
\hline BMI [kg/m²] & $37.39 \pm 6.40$ & $35.95(31.73 ; 42.78)$ & $24.46 \pm 3.06$ & $25.00(21.50 ; 26.95)$ & $<0.0001$ \\
\hline WHR & $0.98 \pm 0.09$ & $0.98(0.93 ; 1.06)$ & $0.83 \pm 0.07$ & $0.82(0.79 ; 0.89)$ & $<0.0001$ \\
\hline SBP [mm Hg] & $143.19 \pm 17.70$ & $140.00(135.00 ; 150.00)$ & $124.59 \pm 19.27$ & $125.00(106.00 ; 139.50)$ & $<0.0002$ \\
\hline DBP [mm Hg] & $89.77 \pm 8.55$ & $90.00(84.25 ; 95.00)$ & $81.33 \pm 10.20$ & $80.00(72.00 ; 91.00)$ & $<0.003$ \\
\hline TC [mmol/l] & $5.67 \pm 1.16$ & $5.84(4.79 ; 6.53)$ & $5.20 \pm 0.82$ & $5.15(4.58 ; 5.61)$ & 0.062 \\
\hline HDL [mmol/l] & $1.15 \pm 0.32$ & $1.15(0.97 ; 1.33)$ & $1.76 \pm 0.43$ & $1.78(1.38 ; 1.95)$ & $<0.0001$ \\
\hline LDL [mmol/l] & $3.65 \pm 1.14$ & $3.53(2.89 ; 4.37)$ & $3.24 \pm 0.78$ & $3.26(2.65 ; 3.74)$ & 0.07 \\
\hline TG [mmol/l] & $2.26 \pm 1.05$ & $1.97(1.57 ; 2.75)$ & $1.02 \pm 0.37$ & $0.96(0.77 ; 1.23)$ & $<0.0001$ \\
\hline FBG [mmol/l] & $5.80 \pm 0.93$ & $5.59(5.20 ; 6.16)$ & $4.94 \pm 0.52$ & $4.94(4.55 ; 5.41)$ & $<0.0001$ \\
\hline Ca [mmol/l] & $2.42 \pm 0.18$ & $2.38(2.31 ; 2.51)$ & $2.43 \pm 0.12$ & $2.42(2.37 ; 2.49)$ & 0.2552 \\
\hline PTH [pmol/l] & $4.00 \pm 1.59$ & $3.86(2.88 ; 5.12)$ & $4.27 \pm 1.60$ & $4.13(3.22 ; 5.29)$ & 0.4807 \\
\hline Albumin [ $\mu \mathrm{mmol} / \mathrm{l}]$ & $619.88 \pm 29.27$ & $623.50(594.50 ; 638.00)$ & $663.24 \pm 42.29$ & $667.00(623.50 ; 688.75)$ & $<0.0001$ \\
\hline
\end{tabular}

The parameter values are presented as means ( \pm SD) and as medians (25\% and $75 \%$ quartile); $n$-number of studies individuals, $p-s t a t i s t i c a l$ significance level according to the Mann-Whitney U-test for the MetS+vs. MetS-groups in the case of nonparametric distributions or the $T$-test for parametric data, BMI - body mass index, WHR - waist-to-hip ratio, SBP-systolic blood pressure, DBP - diastolic blood pressure, $T C$ - concentration of total cholesterol, HDL - concentration of high-density lipoprotein, $L D L$ - concentration of low-density lipoprotein, $T G$ - concentration of triglycerides, FBG - concentration of glucose, Ca - concentration of calcium, PTH - concentration of parathyroid hormone.

Table II. Concentration of various forms of vitamin D and vitamin D binding protein in individuals with (MetS+) and without metabolic syndrome (MetS-)

\begin{tabular}{|c|c|c|c|c|c|}
\hline Parameter & Met & $(n=52)$ & Met & $(n=27)$ & $P$-value \\
\hline $25(\mathrm{OH}) \mathrm{D}[\mathrm{nmol} / \mathrm{l}]$ & $41.90 \pm 13.12$ & $40.7(34.24 ; 48.41)$ & $66.09 \pm 18.02$ & $65.13(53.25 ; 79.99)$ & $<0.0001$ \\
\hline $\operatorname{VDBP}[\mu \mathrm{mol} / \mathrm{l}]$ & $6.65 \pm 1.73$ & $6.37(5.42 ; 7.66)$ & $7.14 \pm 1.26$ & $6.84(6.14 ; 8.41)$ & 0.1941 \\
\hline $\begin{array}{l}\text { Free } 25(\mathrm{OH}) \mathrm{D} \\
\text { [pmol/l] }\end{array}$ & $9.59 \pm 3.82$ & 8.62 (7.00; 11.68) & $13.55 \pm 4.12$ & $14.73(10.06 ; 16.77)$ & $<0.0001$ \\
\hline $\begin{array}{l}\text { Bioavailable } \\
25(\mathrm{OH}) \mathrm{D}[\mathrm{nmol} / \mathrm{l}]\end{array}$ & $3.56 \pm 1.39$ & $3.08(2.63 ; 4.42)$ & $5.39 \pm 1.65$ & $5.71(4.14 ; 6.71)$ & $<0.0001$ \\
\hline
\end{tabular}

The parameter values are presented as means ( \pm SD) and as medians (25\% and $75 \%$ quartile); $n$ - number of studies individuals, $p$ - statistical significance level according to the Mann-Whitney U-test for the MetS+ vs. MetS-groups in the case of nonparametric distributions or the T-test for parametric data, 25(OH)D - concentration of 25-hydroxyvitamin D, VDBP - concentration of vitamin D binding protein, free $25(\mathrm{OH}) D$ - concentration of free 25 -hydroxyvitamin $D$, bioavailable $25(\mathrm{OH}) D$ - concentration of bioavailable 25-hydroxyvitamin D.

components of metabolic syndrome (SBP, DBP, HDL, TG, FBG) (Table III). In the case of the concentration of free and bioavailable vitamin $D$, a correlation was observed with the results of the anthropometric analysis, and to a lesser extent with the biochemical parameters (HDL, TG). Moreover, for the level of vitamin D binding protein, there was also a correlation with fewer anthropometric (body weight, BMI) and bio- chemical components (SBP, DBP, FBG). None of these relations were found to hold in the case of calcium or of parathyroid hormone. In the entire research group, 25(OH)D concentration correlated positively with the concentration of free $(r=0.7940, p<0.0001)$ and bioavailable $(r=$ $0.8171, p<0.0001)$ forms of vitamin $D$, whereas VDBP concentration showed a negative relationship with those parameters $(r=-0.4260$, 
Table III. Pearson correlation coefficient $(r)$ and statistical significance level $(p)$ of concentrations of 25-hydroxyvitamin $\mathrm{D}(25(\mathrm{OH}) \mathrm{D})$, free $25(\mathrm{OH}) \mathrm{D}$, and the bioavailable fraction of $25(\mathrm{OH}) \mathrm{D}$, as well as vitamin $\mathrm{D}$ binding protein, for the selected anthropometric and biochemical parameters of the entire studied population $(n=79)$

\begin{tabular}{|c|c|c|c|c|c|c|c|c|}
\hline \multirow[t]{2}{*}{ Parameter } & \multicolumn{2}{|c|}{$25(\mathrm{OH}) \mathrm{D}$} & \multicolumn{2}{|c|}{ Free $25(\mathrm{OH}) \mathrm{D}$} & \multicolumn{2}{|c|}{ Bioavailable 25(OH)D } & \multicolumn{2}{|c|}{ VDBP } \\
\hline & $r$ & $p$ & $r$ & $p$ & $r$ & $p$ & $r$ & $p$ \\
\hline Body weight [kg] & -0.4740 & $<0.0001$ & -0.2892 & 0.010 & -0.3357 & 0.003 & -0.2363 & 0.036 \\
\hline $\begin{array}{l}\text { Waist circumference } \\
{[\mathrm{cm}]}\end{array}$ & -0.5395 & $<0.0001$ & -0.3889 & $<0.0001$ & -0.4414 & $<0.0001$ & -0.1612 & 0.156 \\
\hline $\mathrm{BMI}\left[\mathrm{kg} / \mathrm{m}^{2}\right]$ & -0.5498 & $<0.0001$ & -0.3464 & 0.002 & -0.3998 & $<0.0001$ & -0.2678 & 0.017 \\
\hline WHR & -0.3860 & $<0.0001$ & -0.3709 & 0.001 & -0.4057 & $<0.0001$ & -0.0664 & 0.561 \\
\hline $\mathrm{SBP}[\mathrm{mm} \mathrm{Hg}]$ & -0.2697 & 0.016 & -0.0720 & 0.528 & -0.1252 & 0.272 & -0.2327 & 0.039 \\
\hline $\mathrm{DBP}[\mathrm{mm} \mathrm{Hg}]$ & -0.3106 & 0.005 & -0.1149 & 0.313 & -0.1429 & 0.209 & -0.2876 & 0.010 \\
\hline $\mathrm{HDL}[\mathrm{mmol} / \mathrm{l}]$ & 0.4879 & $<0.0001$ & 0.4253 & $<0.0001$ & 0.4400 & $<0.0001$ & 0.0396 & 0.729 \\
\hline TG $[\mathrm{mmol} / \mathrm{l}]$ & -0.3969 & $<0.0001$ & -0.3287 & 0.003 & -0.3459 & 0.002 & -0.0413 & 0.718 \\
\hline FBG [mmol/l] & -0.2790 & 0.013 & -0.1114 & 0.557 & -0.1492 & 0.189 & -0.2304 & 0.041 \\
\hline
\end{tabular}

$B M I$ - body mass index, WHR - waist-to-hip ratio, SBP - systolic blood pressure, DBP - diastolic blood pressure, HDL - concentration of high-density lipoprotein, $T G$ - concentration of triglycerides, $F B G$ - concentration of glucose.

$p<0.0001$ for free $25(\mathrm{OH}) \mathrm{D}$ and $r=-0.3847$, $p<0.0001$ for bioavailable $25(\mathrm{OH}) \mathrm{D}$, respectively).

In the MetS+ group, there were no relations between the total amount of $25(\mathrm{OH}) \mathrm{D}$ concentration, its free or bioavailable fraction, and metabolic syndrome components. Such relations were found, however, in the case of VDBP concentration, which negatively correlated with BMI values $(r=-0.2897, p=0.037)$, hip circumference $(r=-0.3108, p=0.025)$, and diastolic blood pressure levels $(r=-0.3171, p=0.022)$. In the MetS+ group, WHR showed a negative relationship with HDL cholesterol concentration $(r=-0.3009$, $p=0.030)$ and a positive one with triglyceridemia $(r=0.3919, p=0.004)$.

In both the Mets+ and MetS-groups, as in the entire studied population, the concentration of $25(\mathrm{OH}) \mathrm{D}$ correlated positively with the concentration of free $(r=0.7003, p<0.001$ for the MetS+ group and $r=0.8061, p<0.001$ for the MetSgroup) and bioavailable fraction of $25(\mathrm{OH}) \mathrm{D}$ $(r=0.7111, p<0.001$ for the MetS+ group and $r=7831, p<0.001$ for the MetS- group), whereas VDBP concentration showed a negative relationship with these parameters $(r=-0.5959$, $p<0.0001$ for free $25(\mathrm{OH}) \mathrm{D} ; r=-0.5960, p<$ 0.0001 for the bioavailable fraction of $25(\mathrm{OH}) \mathrm{D}$ in the MetS+group and $r=-0.4706, p=0.013$ for free $25(\mathrm{OH}) \mathrm{D} ; r=-0.4752, p=0.012$ for the bioavailable fraction of $25(\mathrm{OH}) \mathrm{D}$ in the MetS-group).

In the case of patients lacking metabolic syndrome, no relationships were found for the concentration of $25(\mathrm{OH}) \mathrm{D}$ or bioavailable vitamin $\mathrm{D}$, whereas the free fraction negatively correlated with triglyceridemia $(r=-0.3824, p=0.049)$. Furthermore, in this group, the anthropometric mark- ers (BMI and WHR) correlated positively with glycemia $(r=0.5291, p=0.005 ; r=0.5086, p=0.007$ respectively). Additionally, $\mathrm{BMI}$ negatively correlated with the concentration of $\mathrm{HDL}$ cholesterol $(r=-0.4176, p=0.031)$.

\section{Discussion}

Epidemiological data show that vitamin D deficiency in various populations has become a common phenomenon. It is thought that the decreased concentration of this vitamin in serum may correlate with the occurrence of metabolic diseases [18-20]. In the present study, the concentration of $25(\mathrm{OH}) \mathrm{D}$ in serum among the majority of people was lower than the reference values $(<75 \mathrm{nmol} / \mathrm{l})$. Deficiencies of the hydroxylated form of vitamin D, as well as significantly lower levels of the free and bioavailable fraction of the vitamin, were more frequently found in the group of patients with metabolic syndrome than in those without it. The mechanism behind the drop in $25(\mathrm{OH}) \mathrm{D}$ concentration in visceral obesity (the basis for the diagnosis of metabolic syndrome) has not been fully clarified. It is assumed that it may be connected with the presence of a natural barrier in the form of excess adipose tissue, which, alongside other factors, supports vitamin D sequestration, makes its transport into the blood circulation system more difficult, and disturbs its metabolism [4]. Furthermore, Drincic et al. have suggested that vitamin D taken together with food or synthesized in the skin is diluted volumetrically in a large amount of adipose tissue, which results in the occurrence of a significant serum deficiency of this type of compound in obese individuals 
[21]. It is assumed that adipocytes may affect the expression of genes coding for the enzymes that take part in the activation and transformation of vitamin D. Wamberg et al. found that among obese patients, the expression of the genes coding 25-hydroxylase (CYP2J2) and $1 \alpha$-hydroxylase (CYP27B1) is lower in the subcutaneous adipose tissue by respectively $71 \%$ and $49 \%$, compared to people of appropriate body weight; in the case of body weight reduction, the concentration of $25(\mathrm{OH}) \mathrm{D}$ in serum increased by $27 \%$ [22]. On the other hand, the possibility of vitamin D's active participation in the process of adipogenesis and the remodeling of adipose tissue has been shown. In vitro research suggested that $1,25(\mathrm{OH})_{2} \mathrm{D}_{3}$ slows adipogenesis and promotes adipocyte apoptosis of the mouse cell line 3T3-L1 [23], whereas in humans this vitamin may promote the process of adipogenesis, which is associated with the replacement of mature adipocytes by new insulin-sensitive cells of adipose tissue [24].

In our study, the levels of vitamin D binding protein in both groups (research and control) were similar, which was not the case for the individual fractions of vitamin D. The analysis in this area, performed by various research centers, has been ambiguous, and no such research was found dealing with patients with metabolic syndrome. Winters et al. observed similar levels of VDBP among African-American and white women [25], while Oberbach et al. found higher concentrations of this molecule among obese women and men, in comparison with people of appropriate body weight [26]. In other studies, when comparing the concentration of VDBP between obese and normal weight women, an increase in its level was also observed in the obese individuals. It is assumed that the concentration of vitamin $D$ binding protein in the case of women may be modulated by the level of estrogens affecting its hepatic production [27]. Moreover, three VDBP allelic variants (Gc1s, Gc1f, Gc2) can be distinguished; these condition affect the serum concentration of VDBP [28].

In our analysis, the concentration of the hydroxylated form of vitamin $D$ in the whole population is negatively correlated with all the components of metabolic syndrome. These data are in agreement with the results of the analysis of other researchers $[3,4]$. The meta-analysis performed by Khan et al., which evaluated the occurrence of relations between the serum concentration of $25(\mathrm{OH}) \mathrm{D}$ and the risk of metabolic diseases and of type-2 diabetes mellitus, showed that low levels of this vitamin predispose to these disorders [29]: vitamin D can stimulate the activity of the renin-angiotensin-aldosterone system, endothelium function, or pancreatic $\beta$-cell function, and a protective role in the prevention of metabolic diseases is therefore attributed to it [30].

A positive correlation of free and bioavailable vitamin D with the $25(\mathrm{OH}) \mathrm{D}$ form, and a negative correlation with VDBP level, were observed in our study, both for the whole population and in the two groups separately. Similar results were also obtained in the research of Wang et al. [31]. Additionally, our analysis showed the existence of negative correlations between the concentration of free and bioavailable forms of vitamin $D$ and the prevalence of particular components of metabolic syndrome in the entire studied population; for individuals without this syndrome, only the free fraction of the vitamin is negatively correlated with triglyceridemia. Experimental studies on mice have shown that vitamin $D$ binding protein may be considered an inhibitor of the free fraction of vitamin $D$ which, by binding its hydroxylated forms, allows them to be transported in the body; it also regulates their availability to specific cells, tissues, and organs [10]. Unlike the free fraction of vitamin D, VDBP does not have an influence on the bioavailable fraction of the vitamin (i.e., the albumin-bound vitamin D plus the free fraction). It is estimated that the bioavailable fraction of vitamin D constitutes about $10 \%$ of all forms of this compound and may be an alternative to $25(\mathrm{OH}) \mathrm{D}$ indicators in some clinical trials [7]. The establishment of reference values for 25-hydroxyvitamin $D$ and its free fraction has been the subject of much discussion. Further population studies on various forms of vitamin D are therefore required, especially because of their role in the maintenance of human health. Moreover, it is important to establish clinical recommendations for these compounds. The measurement of free $25(\mathrm{OH}) \mathrm{D}$ is generally labor-intensive (using ELISA strategies) and is not yet commercially available. The earliest work in this area did not allow this analysis to be used in routine clinical practice. As a consequence, alternative methods based on mathematical models are useful in estimating the free and bioavailable forms of vitamin $D$, which can be meaningful markers of vitamin D status [32, 33].

The results of our research indicate that vitamin D binding protein negatively correlates with body weight, BMI, levels of arterial blood pressure, and glycemia in the whole population. For people with metabolic syndrome, VDBP level negatively correlates with anthropometric parameters (hip circumference and $\mathrm{BMI}$ ) and levels of diastolic pressure. Investigations by other researchers into the correlation between VDBP and anthropometric parameters vary in their results. Negative [32, 34] and positive [35] correlations of vitamin D binding protein with body weight and BMI are shown, or such correlations are not demonstrated 
$[12,25]$. On the other hand, with regard to the bio chemical components of metabolic syndrome, it is suggested that the protein may be a protective agent against their occurrence. In the analysis of Speeckaert et al., negative correlations between the VDBP concentration and the fraction of LDL lipoproteins, as well as triglyceridemia, were observed [36]. In addition, it is thought that VDBP, by regulating the amount of active vitamin $D$ in $\beta$-cells of the pancreas, may affect insulin secretion, and thus affect the prevalence of insulin resistance and type-2 diabetes mellitus [11].

The research model presented here has some limitations. The first is the size of the research and control groups, which translates into difficulties in dividing them into smaller subgroups that might take account of the impact of sunlight on the endogenous production of vitamin D, as well as other factors. Furthermore, only Caucasians participated in the study, and so the results should be generalized with caution. Additionally, the research included people with varying degrees of metabolic syndrome, presenting three, four, or five of its components; however, in accordance with the definition of metabolic syndrome, there is a broad population of people at risk of various metabolic disorders (obesity, hypertension, hyperglycemia, dyslipidemia). Another limitation of this research is that it takes into consideration the mathematically calculated concentrations of the free and bioavailable fraction of $25(\mathrm{OH}) \mathrm{D}$. In practice, these formulas are used and accepted, and including them in the research allows the analysis to be expanded to include a complex evaluation of various forms of vitamin $D$ in the human body. Nevertheless, the results of this research show that relations do exist between the various forms of vitamin $D$ and vitamin $D$ binding protein concentrations and the prevalence of metabolic disorders, and thus form the basis for further, more extensive research in this area.

In conclusion, statistically significant differences were found in the concentration of 25-hydroxyergocalciferol and 25-hydroxycholecalciferol $(25(\mathrm{OH}) \mathrm{D})$, as well as of the free and bioavailable fraction of vitamin $D$, between people with and without metabolic syndrome. Such relations were not observed in the case of vitamin D binding protein. Moreover, significant correlations were noted between the concentrations of vitamin $D$ and VDBP in various forms and the presence of particular components of metabolic syndrome, both in the entire study population and in the research and control groups separately. Thus, the evaluation of various forms of vitamin $D$ and vitamin $D$ binding protein in different population groups seems to have significant clinical value for evaluating the prevalence of metabolic syndrome.

\section{Acknowledgments}

This study was part funded by Poznan University of Medical Sciences, grant numbers: 502-1402228371-99662 and 502-01-02228371-04458.

\section{Conflict of interest}

The authors declare no conflict of interest.

\section{References}

1. Pacholczyk M, Ferenc T, Kowalski J. The metabolic syndrome. Part II: Its mechanisms of development and its complications. Post Hig Med Dosw 2008; 62: 543-58.

2. Holick MF. Vitamin D deficiency. N Engl J Med 2007; 357: 266-81.

3. Mozos I, Marginean O. Links between vitamin D deficiency and cardiovascular diseases. BioMed Res Int 2015; 2015: 109275.

4. Wang C. Role of vitamin D in cardiometabolic diseases. J Diabetes Res 2013; 2013: 243934.

5. Ding C, Gao D, Wilding J, Trayhurn P, Bing C. Vitamin signaling in adipose tissue. Br J Nutr 2012; 108: 1915-23.

6. Holick MF, Chen TC. Vitamin D deficiency: a worldwide problem with health consequences. Am J Clin Nutr 2008; 87: 1080-6.

7. Chun RF, Peercy BE, Orwoll ES, Nielson CM, Adams JS, Hewison M. Vitamin D and DBP: the free hormone hypothesis revisited. J Steroid Biochem Mol Biol 2014; 144: $132-7$.

8. Chun RF. New perspectives on the vitamin D binding protein. Cell Biochem Funct 2012; 30: 445-56.

9. Speeckaert MM, Huang G, Delanghe JR, Taes YE. Biological and clinical aspects of the vitamin $D$ binding protein (Gc-globulin) and its polymorphism. Clin Chim Acta 2006; 372: 3-42.

10. Safadi FF, Thornton P, Magiera H, et al. Osteopathy and resistance to vitamin $D$ toxicity in mice null for vitamin D binding protein. J Clin Investig 1999; 103: 239-51.

11. Ashraf AP, Huisingh C, Alvarez JA, Wang X, Gower BA. Insulin resistance indices are inversely associated with vitamin D binding protein concentrations. J Clin Endocrinol Metab 2014; 99: 178-83.

12. Weinstein SJ, Stolzenberg-Solomon RZ, Kopp W, Rager H, Virtamo J, Albanes D. Impact of circulating vitamin $D$ binding protein levels on the association between 25-hydroxyvitamin $D$ and pancreatic cancer risk: a nested case-control study. Cancer Res 2012; 72 : 1190-8.

13. Alberti KG, Eckel RH, Grundy SM, et al. Harmonizing the metabolic syndrome. A joint interim statement of the International Diabetes Federation Task Force on Epidemiology and Prevention; National Heart, Lung, and Blood Institute; American Heart Association; World Heart Federation; International Atherosclerosis Society; and International Association for the Study of Obesity. Circulation 2009; 120: 1640-5.

14. Mancia G, Fagard R, Narkiewicz K, et al. Task Force Members. 2013 ESH/ESC Guidelines for the management of arterial hypertension: The Task Force for the management of arterial hypertension of the European Society of Hypertension (ESH) and of the European Society of Cardiology (ESC). J Hypertens 2013; 31: 1281-357.

15. Bikle DD, Gee E, Halloran B, Kowalski MA, Ryzen E, Haddad JG. Assessment of the free fraction of 25-hydroxyvitamin D in serum and its regulation by albumin and 
the vitamin D-binding protein. J Clin Endocrinol Metab 1986; 63: 954-9

16. Vermeulen A, Verdonck L, Kaufman JM. A critical evaluation of simple methods for the estimation of free testosterone in serum. J Clin Endocrinol Metab 1999; 84: 3666-72.

17. Holick MF, Binkley NC, Bischoff-Ferrari HA, et al. Evaluation, treatment, and prevention of vitamin $D$ deficiency: an Endocrine Society Clinical Practice Guideline. J Clin Endocrinol Metab 2011; 96: 1911-30.

18. Palacios C, Gonzlaez L. Is vitamin D deficiency a major global public health problem? J Steroid Biochem Mol Biol 2014; 144: 138-45.

19. Skaaby T, Husemoen LL, Pisinger C, et al. Vitamin D status and changes in cardiovascular risk factors: a prospective study of a general population. Cardiology 2012; 123: 62-70.

20. Makariou S, Liberopoulos E, Florentin M, et al. The relationship of vitamin $\mathrm{D}$ with non-traditional risk factors for cardiovascular disease in subjects with metabolic syndrome. Arch Med Sci 2012; 8: 437-43.

21. Drincic AT, Armas LA, Van Diest EE, Heaney RP. Volumetric dilution, rather than sequestration best explains the low vitamin D status of obesity. Obesity (Silver Spring) 2012; 20: 1444-8.

22. Wamberg L, Christiansen T, Paulsen SK, et al. Expression of vitamin D-metabolizing enzymes in human adipose tissue - the effect of obesity and diet-induced weight loss. Int J Obes 2013; 37: 651-7.

23. Kong J, Li YC. Molecular mechanism of 1,25-dihydroxyvitamin D3 inhibition of adipogenesis in 3T3-L1 cells. Am J Physiol Endocrinol Metab 2006; 290: 916-24.

24. Nimitphong H, Holick MF, Fried SK, Lee MJ. 25-hydroxyvitamin D3 and 1,25-dihydroxyvitamin D3 promote the differentiation of human subcutaneous preadipocytes. Plos One 2012; 7: e52171.

25. Winters SJ, Chennubhatla R, Wang C, Miller JJ. Influence of obesity on vitamin D-binding protein and 25-hydroxyvitamin $D$ levels in African American and white women. Metabolism 2009; 58: 438-42.

26. Oberbach A, Bluher $\mathrm{M}$, Wirth $\mathrm{H}$, et al. Combined proteomic and metabolomic profiling of serum reveals association of the complement system with obesity and identifies novel markers of body fat mass changes. J Proteome Res 2011; 10: 4769-88.

27. Karlsson T, Osmancevic A, Jansson N, Hulthen L, Holmang A, Larsson I. Increased vitamin D-binding protein and decreased free $25(\mathrm{OH}) \mathrm{D}$ in obese women of reproductive age. Eur J Nutr 2014; 53: 259-67.

28. Lauridsen AL, Vestergaard P, Nexo E. Mean serum concentration of vitamin D-binding protein (Gc globulin) is related to the Gc phenotype in women. Clin Chem 2001 47: 753-6.

29. Khan H, Kunutsor S, Franco OH, Chowdhury R. Vitamin D, type 2 diabetes and other metabolic outcomes: a systematic review and meta-analysis of prospective studies. P Nutr Soc 2013; 72: 89-97.

30. Prasad P, Kochhar A. Interplay of vitamin D and metabolic syndrome: a review. Diabetes Metab Syndr 2016; 10: 105-12.

31. Wang J, Eliassen AH, Spiegelman D, Willett WC, Hankinson SE. Plasma free 25-hydroxyvitamin D, vitamin D binding protein, and risk of breast cancer in the Nurses' Health Study II. Cancer Causes Control 2014; 25: 819-27.

32. Powe CE, Ricciardi C, Berg AH, et al. Vitamin D-binding protein modifies the vitamin $\mathrm{D}$-bone mineral density relationship. J Bone Miner Res 2011; 26: 1609-16.
33. Bhan I, Powe CE, Berg AH, et al. Bioavailable vitamin D is more tightly linked to mineral metabolism than total vitamin $\mathrm{D}$ in incident hemodialysis patients. Kidney Int 2012; 82: 84-9.

34. Powe CE, Seely EW, Rana $S$, et al. First trimester vitamin $D$, vitamin $D$ binding protein, and subsequent preeclampsia. Hypertension 2010; 56: 758-63.

35. Taes YE, Goemaere S, Huang G, et al. Vitamin D binding protein, bone status and body composition in community-dwelling elderly men. Bone 2006; 38: 701-7.

36. Speeckaert MM, Taes YE, De Buyzere ML, Christophe AB, Kaufman JM, Delanghe JR. Investigation of the potentia association of vitamin D binding protein with lipoproteins. Ann Clin Biochem 2010; 47: 143-50. 